\title{
2018 Ortaokul Matematik Dersi Öğretim Programının Sayı Hissi Bileşenlerine Göre İncelenmesi
}

\author{
Sema ACAR ${ }^{1}$ (D) \& Bilge PEKER ${ }^{2 *}$ \\ Gönderilme Tarihi:15 Haziran 2021 Kabul Tarihi: 12 Ekim 2021 \\ DOI: $10.52974 /$ jena. 952589
}

\section{$\ddot{O}_{z}$ :}

Bu çalışmanın amacı 2018 yılı ortaokul matematik dersi öğretim programının sayı hissi ve bileşenlerine göre incelenmesidir. Bu amaç doğrultusunda temel nitel araştırma deseni kullanılmıştır. Araştırmanın veri kaynă̆ı, Millî Ĕ̆itim Bakanlı̆̆ı'nın 2018 yılında yayınlamış olduğu ortaokul matematik dersi öğretim programıdır. Araştırmanın verileri betimsel analiz yoluyla analiz edilmiştir. Çalışma sonucunda öğretim programında yer alan 215 kazanımdan 62'sinin sayı hissi ile ilişkili olduğu belirlenmiştir. Ayrıca sınıf düzeyi arttıkça sayı hissi ile ilişkili olan kazanım sayısının azaldığ tespit edilmiştir. Sınıf düzeylerine göre sayı hissi ile ilişkili kazanım sayısının en fazla olduğu sınıf düzeyi ise 5. sinıftır. Öğrenme alanlarına göre incelendiğinde ögretim programında yer alan sayı hissi ile ilişkili kazanımların büyük çoğunluğunun sayılar ve işlemler öğrenme alanından olduğu görülürken; veri işleme ve olasılık ögrenme alanlarında yer alan tüm kazanımların sayı hissi ile ilişkili olmadı $\breve{g}$ tespit edilmiştir. Programda yer alan sayı hissi ile ilişkili kazanımların sayı hissi bileşenlerine göre incelenmesi sonucunda tüm sinıf düzeylerinde ve tüm ögrenme alanlarında en fazla kazanımın "sayıların anlamı" bileşeninde olduğu sonucuna ulaşılmıştır. Matematiğin daha iyi anlaşılması ve matematik başarısının artırılması için matematik dersi öğretim programı kazanımlarında sayı hissine daha çok yer verilmesi ve sayı hissinin kavram olarak programda yer alması önerilmektedir.

Anahtar Kelimeler: Sayı hissi, sayı hissi bileşenleri, ortaokul matematik dersi ögretim programı.

\begin{abstract}
:
The aim of this study is to examine the 2018 secondary school mathematics curriculum in terms of number sense and components. For this purpose, basic qualitative research design was used. The data source of the study is the Secondary School Mathematics Lesson Curriculum published by the Ministry of National Education in 2018. The data collected in the research were analyzed through descriptive analysis. As a result of the research, it was determined that 62 of 215 gains in the curriculum were related to the number sense. In addition, it was found that as the grade level increases, the number of gains associated with the number sense decreases. According to grade levels, the
\end{abstract}

Atıf:

Acar, S. \& Peker, B. (2021) 2018 ortaokul matematik dersi öğretim programının sayı hissi bileşenlerine göre incelenmesi. International Journal of Education and New Approaches, 4(2), 114-128. https://doi.org/10.52974/jena.952589

\footnotetext{
${ }^{1}$ Necmettin Erbakan University, Turkey. Orcid ID: 0000-0002-9989-9612

${ }^{2}$ Necmettin Erbakan University, Turkey. Orcid ID: 0000-0002-0787-4996

*Corresponding Author: bpeker@erbakan.edu.tr
} 
highest possible the number of gains associated with the number sense is 5th grade. When examined in terms of learning areas, it is seen that the majority of the associated with the number sense gains in the program are from the learning areas of numbers and operations, while all gains involved in data processing and probability loading are not associated with the number sense. As a result of the analysis of number sense components number of gains associated with the number sense in the program, it was concluded that the highest gain at all grade levels and in all learning areas was in the "meaning of numbers" component. In order to better understand mathematics and to increase mathematics achievement, it is suggested that including more number sense in mathematics teaching program outcomes and inclusion of the number sense as a concept in the program.

Keywords: Number sense, number sense components, secondary school mathematics curriculum.

\section{GíRIŞ}

Başlangıç noktası tam olarak belli olmasa da 1980 'lerin sonunda Ulusal Matematik Öğretmenleri Konseyi’nin (National Council of Teachers of Mathematics) çalı̧̧malarılla (NCTM, 1989) öne çıkan sayı hissi son yıllarda üzerinde çalışılan konulardan biridir ve önemi sıklıkla vurgulanmaktadır. Literatürde sayı hissiyle ilgili farklı tanımların var olduğu görülmektedir. Hope (1989), sayıların kullanımına ilişkin mantıklı tahminlerde bulunabilme, sayı örüntülerini ve aritmetik hataları fark edebilme, etkili hesaplama yolunu seçebilme hissi olarak tanımlamıştır. Berch'e (2005) göre sayı hissi, sayıların anlamlarına ilişkin sahip olunan duyulardır. Howden (1989) sayı hissinin sayılar ve bunların ilişkileri hakkında iyi bir sezgi olduğunu belirtmiş ve kurallara bağlı olarak yapılan uygulamalar yerine mantığa dayalı çıkarımlar aracılığıyla sonuca ulaşabilmek için farklı yöntemlerin olduğunu fark edebilme becerisi olarak tanımlamışır. Kayhan Altay (2010) sayı hissi yerine sayı duyusu kavramını kullanmış, bu kavramı sayıları esnek bir şekilde kullanma, sayılar ve işlemlerde pratik düşünme, en kullanışlı ve etkili çözüm yolunu seçme, problemi kolaylaştıracak şekilde referans noktası kullanma becerisi olarak tanımlamıştır. Burns (2007) ise, sayı hissinin makul tahminler yapma, esnek düşünme gibi geniş becerileri kapsadığını belirtmiş̧ir.

Sayı hissi tanımlandıktan sonra onun bileşenleri için sınıflandırmalar yapılmaya çalışılmış̧ır. Ancak tanımında olduğu gibi sayı hissinin bileşenleri konusunda da ortak bir noktaya varılamamıştır. Greeno (1991), esnek zihinsel hesaplama, sayısal tahmin ve nicel yargılama olmak üzere 3 bileşenden söz etmiştir. Markovits ve Sowder (1994) sayı hissinin; sayı büyüklüğ̈̈, zihinsel hesaplama ve hesaplama tahmini olmak üzere üç bileşeni olduğunu vurgulamışlardır. Reys ve arkadaşları (1999) ise yaptıkları çalışmada sayı hissinin 6 bileşeni olduğunu belirtmiş̧lerdir. Bu bileşenler; sayıların anlamını ve büyüklüğünü anlama, sayıların eş değer temsillerini anlama ve kullanma, eşdeğer olan ifadelerin anlaşılması ve kullanılması, işlemlerin anlam ve etkilerini anlama, zihinsel hesaplama, yazılı hesaplama ve hesap makinesi kullanımı için esnek hesaplama stratejileri ve ölçüm kriterleridir. Yang (1995) tarafından ortaya atılan bileşenler ise sayıların anlamı, sayıları ayrıştırma ve yeniden birleştirme, sayı büyüklükleri, işlemlerin sayılar üzerine olan etkisini anlama, sayılarla ve işlemlerle hesaplama durumlarında esneklik ve referans noktası kullanımıdır. Gülbağcı Dede ve Şengül (2016: 286) çalışmalarında ölçme bakımından kolaylık sağlaması açısından sayı hissini temel bileşenler olarak ele almışlardır. Çalışmalarında kullandıkları sayı hissi bileşenleri aşağıda açıklanmııstır.

"Sayıların anlamı bileşeni; tam sayılar, kesirler ve ondalık sayıları içeren onluk sayı sistemini, basamak değerini, sayı örüntülerini ve sayıların farklı biçimlerdeki temsillerini içermektedir (McIntosh \& diğ., 1992). Örneğin; bir sayının eş değer gösterimleri (1=e ya da $1 / 4=0,25=\% 25$ gibi); sayılar arasındaki ilişkilerin keşfedilmesi $(8,16$ 'nın yarısı ve 2 'nin küpü olduğunu bilme), sayıyı parçalama/bileştirme $(26$ sayısını $26=(100 \div 4)+1$ şeklinde 
gösterme), basamak değerini kavrama (162 sayısını 100+60+2 formunda düşünebilme) bu bileşen kapsamındadır.

Sayıların büyüklüğ̈̈ bileşeni; tam sayılar, kesirler ve ondalık sayıları ya da sayılarla oluşturulan ifadeleri büyüklük olarak karşılaştırmayı, küçükten büyüğe/büyükten küçüğe doğru sıralamayı, sayıların birbirine olan uzaklıklarını karşılaştırmayı içermektedir. $\mathrm{Bu}$ bileşene; 0,55 'in 0,6 ' dan küçük olduğunu bilme, kesirleri büyüklük olarak karşılaştırma, 22 'nin 23 'e 22 'den daha uzak olduğunu fark etme örnek olarak verilebilir.

Esnek işlem yapma ve sonucun akla yatkınlığını yargılama bileşeni ile kastedilen matematiksel hesaplamalarda sonuca ulaşmak ve sonucu yargılamak için sayı ve işlem bilgisini kullanarak zihinden işlem, tahmin etme gibi becerileri ile esnek işlem yapılmasıdır. Örneğin 1/3'ten küçük üç kesrin toplamının 1'den küçük olduğunu fark etme, 0 ile 1 arasındaki bir sayı ile çarpmanın sonucu küçülttüğünü bilme, iki sayının çarpımı sorulduğunda sayıları yuvarlayarak yakın bir sonuç bulma bu bileşen kapsamında yer almaktadır.

Tahmin etme bileşeni, bir şeyin büyüklüğü ya da ölçüsü hakkında saymadan ve ölçüm yapmadan hızlı ve akla yatkın bir şekilde fikir yürütmektir (Micklo, 1999). Tahmin etme bileşenine 10 katlı bir apartmanın yüksekliğinin, 20 sınıflı bir okuldaki öğrenci mevcudunun, haritada iki şehir arasındaki uzaklığın tahmin edilmesi gibi örnekler verilebilir." (Gülbağc1 Dede \& Şengül, 2016: 286)

Şengül ve Gülbağcı Dede (2013), yaptıkları çalışmada literatürde sayı hissi için yapılan farklı bileşenleri inceleyerek bu kavram için genel bir çerçeve çizilmesini amaçlamışlardır. Çalışma sonucunda sayı hissi bileşenleri için ortak bir terminoloji oluşturulamadığ kapsayan bileşenler için farklı isimlendirmeler kullanıldığı ve farklı yaş grupları için farklı bileşenler kullanıldığı sonucuna varılmıştır.

NCTM (Ulusal Matematik Öğretmenleri Konseyi) ise "Principles and Standards for School Mathematics" (2000) de sayı hissinin matematikteki temel fikirlerden biri olduğuna vurgu yaparak sayı hissine sahip çocukların yapabileceklerini şu şekilde belirtmiştir: (1) Sayıların anlamını anlar. (2) Sayılar ve işlemler arasındaki ilişkileri anlar. (3) Sayıların birbirlerine göre büyüklüklerini tanır. (4) İşlemlerin sayılar üzerinde olan etkilerini anlar. (5) Ölçümler yapabilmek için referans noktaları geliştirir ve kullanır. Aynı zamanda sayı hissi matematiksel düşünmenin gelişimini desteklemekte olup öğrencilerin problemin çözümü için, hangi stratejileri kullanması gerektiği noktasında önemli bir rol oynamaktadır (McIntosh \& diğ., 1992).

Matematik programlarında sayı hissi öğretiminin yer almasının gerekliliği birçok araştırma ve raporda vurgulanmaktadır (Anghileri, 2006; Kilpatrick \& diğ., 2001; Sowder \& Schappelle, 1989; Verschaffel \& diğ., 2007). Aynı zamanda sayı hissi ile matematik başarısı arasında anlamlı bir ilişkinin olduğunu belirten çalışmalar mevcuttur (Harç, 2010; Mohamed \& Johnny, 2010; Yang \& diğ., 2008). Ayrıca literatürde sayı hissinin matematik için önemli olan bazı becerilerle ilişkisi olduğu da görülmektedir. Sayı hissi ile problem çözme becerisi (Işık \& Kar, 2011; Louange \& Bana, 2010), cebirsel düşünme becerisi (Acar \& Peker, 2019), uzamsal yetenek (Günkaya, 2018) ve matematik özyeterliliği (Şengül \& Gülbağcı, 2013, Takır, 2016) arasında pozitif ve anlamlı ilişkiler olduğu görülmektedir. Bu önemine rağmen yapılan çalışmalar genel olarak öğrencilerin sayı hissinin düşük düzeyde olduğunu göstermektedir (Acar \& Peker, 2019; Facun \& Nool, 2002; Harç, 2010; İymen, 2012; Kartal, 2016; Kayhan 
Altay, 2010; Mohamed \& Johnny, 2010; Singh, 2009; Yang, 2005; Yap1c1, 2013). Ayn1 zamanda öğretmen adayları ve öğretmenlerin de sayı hissinin düşük düzeyde olduğu görülmektedir (Kaminski, 1997; Kayhan Altay \& Umay, 2011; Şengül \& Gülbağcı Dede, 2014; Tsao \& Lin, 2011; Yang, 2007). Griffin (2004) ise sayı hissinin, öğrenilebilen ve öğretilebilen bir kavram olduğunu vurgulamaktadır. Dolayısıyla öğrencilerde sayı hissinin geliştirilmesi konusunda en önemli görev öğretmenlere düşmektedir. Tsao ve Lin (2011: 3) "Öğretmenler oluşturdukları sınıf ortamının çeşidi, kullandıkları öğretim uygulaması ve seçtikleri etkinlikler ile sayı hissinin yapılanmasında önemli rol oynamaktadır." sözleriyle sayı hissi eğitiminde öğretmenlerin önemine vurgu yapmışlardır. Bu konuda yapılmış çalışmalar da mevcuttur. Yang (2002) tarafından yapılan bir çalışmada sayı hissinin iletişim ve tartışmalarla geliştiği, tek bir aktivite yerine resimsel temsilden sembolik gösterime çoklu etkinliklerin yapılmasının sayı hissini geliştirdiği sonucuna varılmıştır. Tsao (2004) çalışmasında problem çözme temelli matematik eğitiminin öğretmen adaylarının sayı hissini geliştirdiği sonucuna ulaşmıştır. Yang (2003), araştırmasının sonucunda gerçek hayat problemlerinin öğrencilerin sayı hislerini geliştirmede oldukça etkili olduğunu belirtmiştir. Benzer bir çalışma Yang ve Wu (2010) tarafından yapılmıştır. Araştırma sonucunda matematik derslerinde kullanılan gerçekçi etkinliklerin sayı hissinin gelişimine olumlu etkisi olduğu belirlenmiştir. Araştırmalardan da görüldüğg̈ gibi öğretmenlerin sağlayacağı öğrenme ortamları sayı hissinin gelişiminde oldukça önemlidir. Ayrıca öğretmenlere rehberlik eden öğretim programları ve kaynak olan ders kitaplarının da sayı hissini geliştirmedeki önemi göz ardı edilmemelidir.

\section{Araştırmanın Amacı}

Sayı hissi son yıllarda üzerinde çalışılan konulardan biridir ve önemi sıklıkta vurgulanmaktadır. Öğrencilere sayı hissinin kazandırılmasında ise en önemli görev öğretmenlere düşmektedir. Öğretmenlere kılavuzluk eden kaynaklardan biri ise öğretim programlarıdır. Dolayısıyla öğretim programlarında sayı hissine gereken önemin verilmesi gerektiği düşünülmektedir. Ülkemiz matematik dersi öğretim programlarında doğrudan olmasa da sayı hissinin yansımaları görülmektedir. Matematik eğitiminin genel amaçlarında zihinden işlem yapma ve tahmin becerilerine değinilmektedir. Ancak sayı hissi ile ilişkili ve sayı hissini geliştirebilecek kazanımlara yer verilmesinin de önemli olacağı düşünülmektedir. Bu kapsamda araştırmanın amacı 2018 yılı ortaokul matematik dersi öğretim programının sayı hissi ve bileşenlerine göre incelenmesidir. Programın sayı hissi ve bileşenlerine göre incelenmesi ülkemizde sayı hissine verilen önemi yorumlamak adına alana önemli bir katkı sağlayacaktır. Ayrıca gelecekte yapılacak program değişikliklerine sayı hissi anlamında katkı sağlayacağı düşünülmektedir. Bu anlamda çalışmanın en genel araştırma problemi "2018 yılı ortaokul matematik dersi öğretim programında sayı hissi ve bileşenlerine ne düzeyde yer verilmiştir?” şeklinde belirlenmiştir. Araştırmanın alt problemleri ise;

1. 2018 yılı ortaokul matematik dersi öğretim programında sınıf düzeyine göre sayı hissine ve sayı hissi bileşenlerine ne düzeyde yer verilmiştir?

2. 2018 yılı ortaokul matematik dersi öğretim programında öğrenme alanlarına göre sayı hissine ve sayı hissi bileşenlerine ne düzeyde yer verilmiştir?

\section{YÖNTEM}

\section{Araştırmanın Modeli}

Çalışma, temel nitel araştırma deseni (Merriam, 1998, 2009) kullanılarak yürütülmüştür Araştırmacılar her zaman belirli bir durumu, sistemi, kültürü çalışmak ya da kuram oluşturmayı amaçlamayabilirler. Fakat araştırmacı yorumlamacı bir yaklaşımla nitel araştırma yapabilir 
(Merriam, 2009). Bu sebeple araştırma temel nitel araştırma deseni kullanılarak gerçekleştirilmiştir. Çalışmada temel nitel araştırma deseni 2018 y1lı ortaokul matematik dersi ögretim programının sayı hissi ve bileşenlerine göre incelenmesi amacıyla kullanılmıştır.

\section{Veri Kaynă̆ı}

Araştırmanın verilerinin toplanmasında veri toplama yöntemlerinden doküman incelemesinden yararlanılmıştır. Dokümanlar göz ardı edilen kaynaklar olmalarına rağmen temel değerlendirmeler için oldukça yararlı kaynaklardır (Lincoln \& Guba, 1985). Bu kapsamda araştırmanın veri kaynağı, Millî Eğitim Bakanlığı'nın 2018 yılında yayınlamış olduğu Ortaokul Matematik Dersi Öğretim Programıdır. Milli Eğitim Bakanlığı 2018 İlkokul Matematik dersi Matematik Programı daha önce yapılan araştırmalarda incelendiği için ilkokulun devamı niteliğinde olan ortaokul matematik dersi öğretim programı veri kaynağı olarak seçilmiştir.

\section{Verilerin Analizi}

Araştırmada toplanan veriler betimsel analiz yoluyla analiz edilmiştir. Betimsel analiz ile elde edilen veriler, önceden belirlenmiş temalara göre özetlenir ve yorumlanır (Yıldırım \& Şimşek, 2011). Bu araştırmada analiz çerçevesi olarak Gülbağcı Dede ve Şengül'ün (2016) çalışmalarında kullandıkları sayı hissi temel bileşenleri esas alınmıştır. Bu bileşenler giriş bölümünde detaylı olarak ele alınmıştır. Bu bileşenlerin seçilme sebebi; Gülbağcı Dede ve Şengül'ün (2016) ölçme bakımından kolaylık sağlaması için sayı hissini temel bileşenler olarak belirlemeleridir.

Öğretim programında bulunan kazanımlar yukarıda verilen çalışmada yer alan bileşenlere göre incelenirken; kazanım ifadesi ile birlikte kazanım açıklamaları ve kazanıma yönelik örnekler de dikkate alınmıştır. Örnek bir analiz Tablo 1'de verilmiştir.

Tablo 1. Araştırmada Kullanılan Bir Analiz Örneği

\begin{tabular}{|c|c|c|c|}
\hline Sinıf & $\begin{array}{l}\text { Öğrenme } \\
\text { Alanı }\end{array}$ & Kazanım İfadesi & Analiz \\
\hline 5. sinif & $\begin{array}{l}\text { Geometri } \\
\text { ve Ölçme }\end{array}$ & $\begin{array}{l}\text { M.5.2.3.2. Üçgen ve dörtgenlerin çevre } \\
\text { uzunluklarını hesaplar, verilen bir çevre } \\
\text { uzunluğuna sahip farklı şekiller } \\
\text { oluşturur. } \\
\text { Çevre uzunluğunu tahmin etmeye } \\
\text { yönelik çalışmalara yer verilir. }\end{array}$ & $\begin{array}{l}\text { Kazanım ifadesinin açıklamasında analiz } \\
\text { çerçevesinde belirlenen "Tahmin etme" } \\
\text { bileşenine yer verildiğinden kazanımın } \\
\text { sayı hissi ile ilişkili olduğuna karar } \\
\text { verilmiştir. }\end{array}$ \\
\hline 6. sinif & $\begin{array}{l}\text { Sayılar ve } \\
\text { İşlemler }\end{array}$ & $\begin{array}{l}\text { M.6.1.5.1. Kesirleri karşılaştırır, sıralar } \\
\text { ve sayı doğrusunda gösterir. } \\
\text { Kesirleri sıralamada kullanılacak } \\
\text { stratejiler belirlenirken ilk önce } \\
\text { öğrencilerin kendi stratejilerini } \\
\text { oluş̧urmalarına imkân r verilir. } \\
\text { Kullanılabilecek stratejiler: Kesirlerin } \\
\text { bütüne olan yakınlıkları, yarımdan } \\
\text { büyük veya küçük olmaları, yarıma olan } \\
\text { yakınlıkları, birim kesirlerin } \\
\text { karşılaştırılması, payda eşitleme (denk } \\
\text { kesirlerin dikkate alınması). }\end{array}$ & $\begin{array}{l}\text { Kazanım ifadesinde analiz çerçevesinde } \\
\text { belirlenen "Sayıların büyüklügüü" } \\
\text { bileşenine yer verildiğinden kazanımın } \\
\text { sayı hissi ile ilişkili olduğuna karar } \\
\text { verilmiştir. }\end{array}$ \\
\hline 7. sinif & Cebir & $\begin{array}{l}\text { M.7.2.1.1. Cebirsel ifadelerle toplama } \\
\text { ve çıkarma işlemleri yapar. Cebirsel } \\
\text { ifadelerle toplama ve çıkarma işleminde } \\
\text { uygun modeller kullanılır. }\end{array}$ & $\begin{array}{l}\text { Kazanım ifadesinde ve açıklamasında } \\
\text { analiz çerçevesinde belirlenen bileşenlere } \\
\text { yönelik bir ifadeye rastlanılmadığından } \\
\text { kazanımın sayı hissi ile ilişkili olmadığına } \\
\text { karar verilmiştir. }\end{array}$ \\
\hline
\end{tabular}


Özellikle belirtmek gerekir ki araştırmacılar tarafından belirlenen kazanımların sayı hissi ile ilişkili olup olmaması kazanımın öğrenciye sunuluş şekline (Gülbağcı Dede, 2015) ve öğretmenin bu konudaki bilgi ve becerisine bağlıdır. Dolayısıyla burada sayı hissi ile ilişkili bulunmayan bir kazanımın sayı hissini geliştirebilecek öğrenme ortamlarında sunulması sonucunda kazanım sayı hissi ile ilişkilendirilebilir (Gülbağcı Dede, 2015). Bu araştırmada kazanımların öğretim programında yer alan ifadesi, açıklaması ve verilen örneklerle değerlendirilmiştir.

Verilerin geçerlik ve güvenirliğini sağlamak amacıyla verilerin çözümleme sürecinde araştırmacılar birbirinden bağımsız kodlamalar yapmışlardır. Ayrıca araştırmacıların yanı sıra nitel araştırmalar konusunda deneyimli bir uzmanın görüşüne başvurulmuştur. Uzman tarafından yapılan kodlama ile araştırmacılar tarafından yapılan kodlamalar karşılaştırılmış ve gerekli düzenlemeler yapılmıştır. Kodlayıcılar arasında tutarlılık oranı Miles ve Huberman (1994) formülüne (Güvenirlik= (Görüş birliği/Görüş birliğgi+Görüş ayrılığg $)$ x 100) göre \%95 olarak bulunmuştur. Örneğin, "M.7.1.4.4. Doğru orantılı iki çokluk arasındaki ilişkiyi ifade eder." kazanımına yönelik kodlayıcılardan biri sayıların anlamı bileşenine yönelik bir kazanım olduğunu belirtirken diğeri kazanımın sayı hissi ile ilişkili olmadığını belirtmiştir. Kodlayıcılar tarafından yapılan tekrar inceleme sonucunda kazanım ifadesinde ve kazanımın açıklamasında analiz çerçevesinde belirlenen sayıların anlamı bileşeni için kritik olan becerilerden herhangi birine rastlanmadığından kazanımın sayı hissi ile ilişkili olmadığı konusunda görüş birliğine varılmıştır.

\section{BULGULAR}

İlk aşamada tüm sınıf düzeylerinde ve öğrenme alanlarında yer alan kazanım sayıları incelenmiştir.

Tablo 2. 2018 Ortaokul Matematik Dersi Öğretim Programındaki Sınıf Düzeyi ve Öğrenme Alanlarına Göre Kazanım Sayıları

\begin{tabular}{|c|c|c|c|c|c|}
\hline Öğrenme & 5. sinif & 6. sinif & 7. sinif & 8. sinif & TOPLAM \\
\hline Sayılar ve İşlemler & 33 & 32 & 25 & 16 & 106 \\
\hline Cebir & - & 3 & 7 & 13 & 23 \\
\hline Geometri ve Ölçme & 20 & 19 & 12 & 16 & 67 \\
\hline Veri İşleme & 3 & 5 & 4 & 2 & 14 \\
\hline Olasılık & - & - & - & 5 & 5 \\
\hline TOPLAM & 56 & 59 & 48 & 52 & 215 \\
\hline
\end{tabular}

Tablo 2 incelendiğinde 2018 Ortaokul Matematik Dersi Öğretim Programında 5. sınıfta toplam 56, 6. sinifta 59, 7. sinıfta 48 ve 8 . sinifta 52 olmak üzere toplam 215 kazanım olduğu görülmektedir. Öğrenme alanlarına göre incelendiğinde ise tüm sınıf düzeylerinde sayılar ve işlemler öğrenme alanında 106, cebir öğrenme alanında 23, geometri ve ölçme öğrenme alanında 67, veri işleme öğrenme alanında 14, olasılık öğrenme alanında 5 kazanım olduğu görülmektedir. 
2018 Yılı Ortaokul Matematik Dersi Öğgretim Programında Sınıf Düzeyine Göre Sayı Hissine ve Sayı Hissi Bileşenlerine Ne Düzeyde Yer Verilmiştir?

Tablo 3. Sınıf Düzeyine Göre Sayı Hissi ile İlişkili Kazanım Sayısı

\begin{tabular}{llll}
\hline Sınıf Düzeyi & $\begin{array}{l}\text { Sayı hissi ile ilişkili } \\
\text { kazanım sayısı }\end{array}$ & $\begin{array}{l}\text { Toplam } \\
\text { kazanım sayısı }\end{array}$ & Yüzde (\%) \\
\hline 5. sınıf & 28 & 56 & $\% 50$ \\
6. sınıf & 17 & 59 & $\% 28.8$ \\
7. sınıf & 10 & 48 & $\% 20.8$ \\
8. sınıf & 7 & 52 & $\% 13.5$ \\
\hline TOPLAM & $\mathbf{6 2}$ & $\mathbf{2 1 5}$ & $\mathbf{\% 2 8 . 8}$ \\
\hline
\end{tabular}

Tablo 3 incelendiğinde 5. sinıflarda yer alan 56 kazanımın 28'inin, 6. sinıflarda yer alan 59 kazanımın 17'sinin, 7. sinıflarda yer alan 48 kazanımın 10'unun, 8. siniflarda yer alan 52 kazanımın 7'sinin sayı hissi ile ilişkili olduğu görülmektedir. Toplamda bakıldığında ise öğretim programında yer alan 215 kazanımın 62'sinin sayı hissi ile ilişkili olduğu görülmektedir. Ayrıca sınıf düzeyi arttıkça sayı hissi ile ilişkili olan kazanım sayısının azaldığı da görülmektedir.

Tablo 4. Sınıf Düzeyi ve Sayı Hissi Bileşenlerine Göre Kazanım Sayısı

\begin{tabular}{lllll}
\hline $\begin{array}{l}\text { Sınıf } \\
\text { Düzeyi }\end{array}$ & Sayıların anlamı & $\begin{array}{l}\text { Sayıların } \\
\text { büyüklüğ̈̈ }\end{array}$ & $\begin{array}{l}\text { Esnek işlem } \\
\text { yapma ve } \\
\text { sonucun akla } \\
\text { yatkınlığını } \\
\text { yargılama }\end{array}$ & Tahmin etme \\
\hline 5. sınıf & 11 & 7 & 6 & 4 \\
6. sınıf & 7 & 2 & 5 & 3 \\
7. sınıf & 8 & 1 & - & 1 \\
8. sınıf & 5 & 1 & - & 1 \\
\hline TOPLAM & $\mathbf{3 1}$ & $\mathbf{1 1}$ & $\mathbf{1 1}$ & $\mathbf{9}$ \\
\hline
\end{tabular}

2018 yılı ortaokul matematik dersi öğretim programında sayı hissi ile ilişkili kazanımların sayı hissi bileşenlerine göre incelenmesi sonucunda tüm sınıf düzeylerinde en fazla kazanımın, sayıların anlamı bileşeninde olduğu görülmektedir. Sayıların büyüklüğü ve esnek işlem yapma ve sonucun akla yatkınlığını yargılama bileşenine yönelik 11 kazanım olduğu ve tahmin etme bileşenine yönelik 9 kazanım olduğu tespit edilmiştir. Ayrıca 7. ve 8. sınıfta esnek işlem yapma ve sonucun akla yatkınlığını yargılama bileșeni ile ilişkili kazanımın olmadığı görülmüştür.

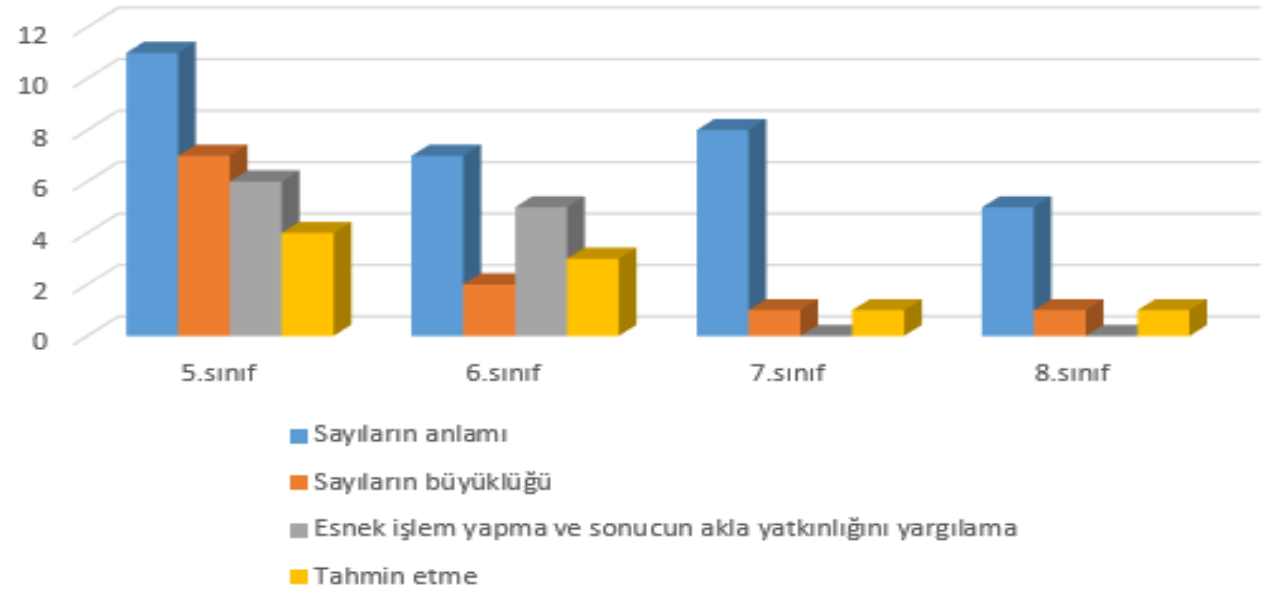

Şekil 1. Sınıf Düzeyi ve Sayı Hissi Bileşenlerine Göre Kazanım Sayısı 
2018 Yılı Ortaokul Matematik Dersi Ö̆̆retim Programında Ö̆̆renme Alanlarında Sayı Hissine ve Sayı Hissi Bileşenlerine Ne Düzeyde Yer Verilmiştir?

Tablo 5. Öğrenme Alanlarına Göre Sayı Hissi İle İlişkili Kazanım Sayısı

\begin{tabular}{llll}
\hline Öğrenme Alanları & $\begin{array}{l}\text { Sayı hissi ile ilişkili } \\
\text { kazanım sayısı }\end{array}$ & $\begin{array}{l}\text { Toplam } \\
\text { kazanım sayısı }\end{array}$ & Yüzde (\%) \\
\hline Sayılar ve İşlemler & 56 & 106 & $\% 50$ \\
Cebir & 1 & 23 & $\% 4.3$ \\
Geometri ve Ölçme & 5 & 67 & $\% 7.5$ \\
Veri İșleme & - & 14 & $\% 0$ \\
Olasılı & - & 5 & $\% 0$ \\
\hline TOPLAM & $\mathbf{6 2}$ & $\mathbf{2 1 5}$ & $\mathbf{\% 2 8 . 8}$ \\
\hline
\end{tabular}

Tablo 5 incelendiğinde sayılar ve işlemler öğrenme alanında yer alan 106 kazanımın 56'sının, cebir öğrenme alanında yer alan 23 kazanımın 1'inin, geometri ve ölçme öğrenme alanında yer alan 67 kazanımın 5'inin sayı hissi ile ilişkili olduğu görülmektedir. Dolayısıyla öğretim programında yer alan sayı hissi ile ilişkili kazanımların büyük çoğunluğunun sayılar ve işlemler öğrenme alanından olduğu belirlenmiştir. Ayrıca veri işleme ve olasılık öğrenme alanlarında yer alan kazanımların sayı hissi ile ilişkili olmadığı tespit edilmiştir.

Tablo 6. Öğrenme Alanları ve Sayı Hissi Bileşenlerine Göre Kazanım Sayısı

\begin{tabular}{lllll}
\hline $\begin{array}{l}\text { Öğrenme } \\
\text { Alanları }\end{array}$ & Sayıların anlamı & $\begin{array}{l}\text { Sayıların } \\
\text { büyüklüğ̈̈ }\end{array}$ & $\begin{array}{l}\text { Esnek işlem } \\
\text { yapma ve } \\
\text { sonucun akla } \\
\text { yatkınlı̆ı̆ı } \\
\text { yargılama }\end{array}$ & Tahmin etme \\
\hline $\begin{array}{l}\text { Sayılar ve İşlemler } \\
\text { Cebir }\end{array}$ & 29 & 11 & 11 & 5 \\
Geometri ve Ölçme & 1 & - & - & - \\
Veri İşleme & 1 & - & - & 4 \\
Olasılık & - & - & - & - \\
\hline TOPLAM & - & - & - & $\mathbf{9}$ \\
\hline
\end{tabular}

2018 yılı ortaokul matematik dersi öğretim programında sayı hissi ile ilişkili kazanımların sayı hissi bileşenlerine göre incelenmesi sonucunda tüm öğrenme alanlarında en fazla kazanımın sayıların anlamı bileşenine ait olduğu görülmektedir. Sayılar ve işlemler öğrenme alanında tüm bileşenlere yönelik kazanımlar varken cebir öğrenme alanında sadece sayıların anlamı bileşenine yönelik kazanım olduğu görülmektedir. Geometri ve ölçme öğrenme alanında ise sayıların anlamı ve tahmin etme bileşenine yönelik kazanımlar olduğu görülmektedir.

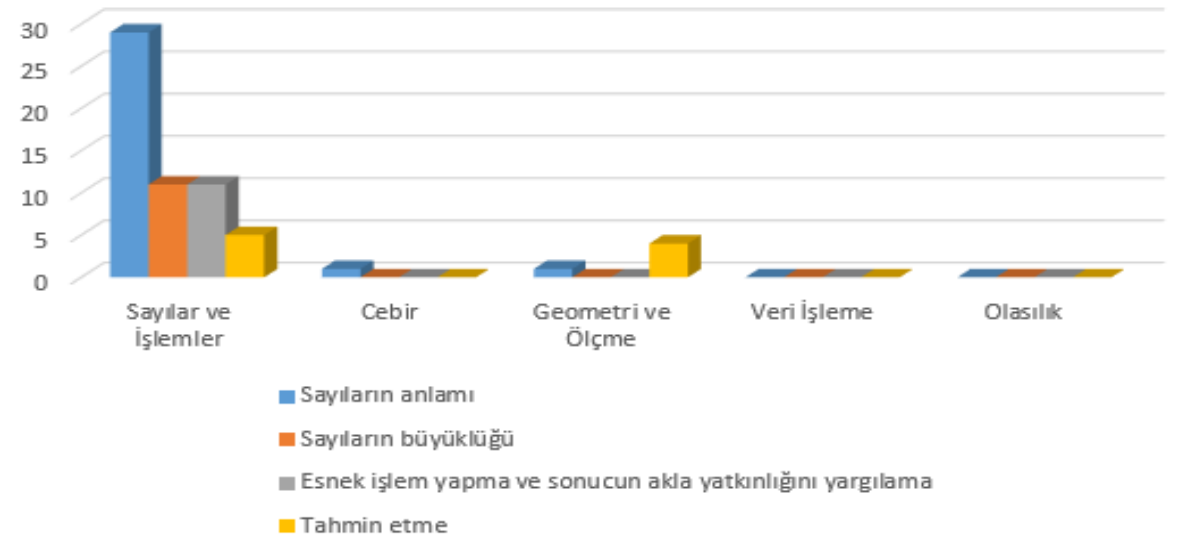

Şekil 2. Öğrenme Alanları ve Sayı Hissi Bileşenlerine Göre Kazanım Sayısı 


\section{TARTIŞMA, SONUÇ ve ÖNERILER}

Sayı hissi son yıllarda üzerinde çalışılan konulardan biridir ve önemi sıklıkta vurgulanmaktadır. Öğrencilere sayı hissinin kazandırılmasında ise en önemli görev öğretmenlere düşmektedir. Öğretmenlere kılavuzluk eden kaynaklardan biri öğretim programlarıdır. Dolayısıyla öğretim programlarında sayı hissine gereken önemin verilmesi gerektiği düşünülmektedir. $\mathrm{Bu}$ çalışmanın amacı 2018 yılı ortaokul matematik dersi öğretim programının sayı hissi ve bileşenlerine göre incelenmesidir. Ülkemiz matematik dersi öğretim programlarında sayı hissi doğrudan yer almasa da matematik eğitiminin genel amaçlarında zihinden işlem yapma ve tahmin becerilerine değinilmektedir. Ayrıca sayı hissi içeren becerilere ilişkin kazanımlar da yer almaktadır. Amaç doğrultusunda yürütülen çalışmanın verileri betimsel analiz yoluyla çözümlenmiştir. Araştırmada analiz çerçevesi olarak Gülbağcı Dede ve Şengül'ün (2016) çalışmalarında kullandıkları 4 temel sayı hissi bileşenleri esas alınmıştır.

Araştırmanın ilk aşamasında sınıf düzeyleri ve öğrenme alanlarına göre toplam kazanım sayıları incelenmiştir. Sonrasında 2018 yılı ortaokul matematik dersi öğretim programında sınıf düzeyine göre sayı hissine ne düzeyde yer verildiğini belirlemek için sayı hissi ile ilişkili toplam kazanım sayıları incelenmiştir. Bu kapsamda 5. sınıflarda yer alan 56 kazanımın 28'inin, 6. sinıflarda yer alan 59 kazanımın 17'sinin, 7. sinıflarda yer alan 48 kazanımın 10'unun, 8. sınıflarda yer alan 52 kazanımın 7'sinin sayı hissi ile ilişskili olduğu belirlenmiştir. Toplamda bakıldığında ise öğretim programında yer alan 215 kazanımın 62'sinin sayı hissi ile ilişkili olduğu görülmüştür. Gülbağcı Dede (2015) tarafından yapılan benzer bir çalışmada 2009 yılı matematik dersi öğretim programı incelenmiştir. Çalışma sonucunda 5. sınıflarda yer alan 40 kazanım, 6 sinıflarda yer alan 22 kazanım, 7. sinıflarda yer alan 13 kazanım ve 8 . sinıflarda yer alan 14 kazanım sayı hissi ile ilişkili bulunmuştur. Dolayısıyla her iki araştırmada da benzer sonuçlara ulaşılmıştır. Sonuç olarak öğretim programında yapılan değişikliklere rağmen sayı hissi ile ilişkili kazanım sayıları benzerlik göstermektedir. Oysa yapılan değişikliklerle sayı hissi ile ilişkili kazanım sayısının artması istenen bir durumdur. Sınıf düzeylerine göre sayı hissi ile ilişkili kazanım sayısının en fazla olduğu sınıf düzeyi 5. sınıftır. Karabey, Tunalı, Olkun ve Ergut (2019) 2013 ve 2017 matematik dersi öğretim programlarında sayı hissi kullanım oranı en fazla olan sınıfın, 5. sınıf olduğu sonucuna ulaşmışlardır. Dolayısıyla bu sonuç araştırmamızın bulguları ile paralellik göstermektedir. Ancak sayı hissi kazanımlarının sadece 5.sınıf düzeyinde yoğunlaşmasının yerine tüm sınıf düzeylerine dengeli bir şekilde dağıtılmasının öğrencileri bu beceriyi kazanması açısından daha verimli olacağı düşünülmektedir. Zira sayı hissi bir anda kazandırılabilecek bir beceri değildir. Sayı hissinin kazandırılmasında süreklilik oldukça önemlidir (Harç, 2010). Bu nedenle, tüm sınıf düzeylerinde sayı hissine yönelik kazanımlara yer verilmesi gereklidir. 2018 y1lı ortaokul matematik dersi öğretim programında sayı hissi ile ilişkili kazanımların sayı hissi bileşenlerine göre incelenmesi sonucunda tüm sınıf düzeylerinde en fazla kazanımın, sayıların anlamı bileşenine ait olduğu görülmüştür. Karabey, Tunalı, Olkun ve Ergut (2019) 2009-2013-2017 matematik dersi öğretim programlarını inceledikleri çalışmada en fazla kullanılan sayı hissi bileşenleri arasında sayıların anlamlarının anlaşılması bileşeni olduğunu belirtmişlerdir. Dolayısıyla farklı araştırma sonuçları çalışmamız ile tutarlılık göstermektedir. Sayıların büyüklüğü ve esnek işlem yapma ve sonucun akla yatkınlığını yargılama bileşenlerine yönelik 11 kazanım olduğu ve tahmin etme bileşenine yönelik 9 kazanım olduğu tespit edilmiştir. Ayrıca 7. ve 8. sınıfta esnek işlem yapma ve sonucun akla yatkınlığını yargılama bileşeni ile ilişkili kazanımın olmadığ 1 görülmüştür. 
2018 yılı ortaokul matematik dersi öğretim programında öğrenme alanlarına göre sayı hissine ne düzeyde yer verildiği incelendiğinde, sayılar ve işlemler öğrenme alanında yer alan 106 kazanımın 56'sının, cebir öğrenme alanında yer alan 23 kazanımın 1'inin, geometri ve ölçme öğrenme alanında yer alan 67 kazanımın 5'inin sayı hissi ile ilişkili olduğu belirlenmiştir. Dolayısıyla öğretim programında yer alan sayı hissi ile ilişkili kazanımların büyük çoğunluğunun sayılar ve işlemler öğrenme alanından olduğu görülürken, veri işleme ve olasılık öğrenme alanlarında yer alan kazanımların sayı hissi ile ilişkili olmadığı tespit edilmiştir. Çetin ve Öztürk (2020) 2018 yılı ilkokul matematik dersi öğretim programında en fazla sayılar ve işlemler öğrenme alanında sayı hissi ile ilişkili kazanım olduğu sonucuna ulaşmışlardır. Dolayısıyla iki araştırmanın bulguları uyumludur. Sayı hissi ile ilişkili kazanım sayısının en fazla sayılar ve işlemler öğrenme alanında olması beklenen bir durum olmakla birlikte istenen bir durum değildir. Çünkü sayılar sadece sayılar ve işlemler öğrenme alanında yer almamaktadır. Cebirsel ifadeler, özdeşlikler, denklemler, eşitsizlikler içerisinde yer alan sayılar için de sayı hissi gerekli bir beceridir. Ayrıca sayı hissi sadece sayılarla sınırlı bir beceri değildir. Tüm öğrenme alanlarında yer alması gereken bir beceridir. 2018 yılı ortaokulu matematik dersi öğretim programında sayı hissi ile ilişkili kazanımların sayı hissi bileşenlerine göre incelenmesi sonucunda tüm öğrenme alanlarında en fazla kazanımın sayıların anlamı bileşeninde olduğu tespit edilmiştir. Sayılar ve işlemler öğrenme alanında tüm bileşenlere yönelik kazanımlar varken cebir öğrenme alanında sadece sayıların anlamı bileşenine yönelik kazanım olduğu belirlenmiştir. Geometri ve ölçme öğrenme alanında ise sayıların anlamı ve tahmin etme bileşenine yönelik kazanım olduğu görülmüştür.

Amerika Birleşik Devletinin New Jersey eyaletinde matematik programı için belirlenen standartlarda sayı hissi, matematiği başarılı bir şekilde kullanan bireylerin ortak özelliği olarak gösterilmiştir (Rosenstein \& diğ., 1996). Kaminski (2002) ise öğrencilerin matematiği anlaması ve etkili kullanma başarısının sayı hissinin gelişimiyle mümkün olabileceğini belirtmiştir. Dolayısıyla matematiğin daha iyi anlaşılması ve matematik başarısının artırılması için matematik dersi öğretim programı kazanımlarında sayı hissine daha çok yer verilmesi önerilmektedir. Matematik dersi öğretim programlarına sayı hissine yönelik kazanımların eklenmesi ve diğer kazanımları ile bütünleştirilmesi öğrencilerde sayı hissinin geliştirilmesi adına önem taşımaktadır (Takır, 2016). Bunun yanı sıra sayı hissi ile ilişkili kazanım sayısının tüm sınıflarda ve tüm öğrenme alanlarında dengeli bir biçimde dağıtılması önerilmektedir. Çünkü sayı hissi bir anda kazandırılabilecek bir beceri değildir. Bu yüzden tüm sınıf düzeylerinde yer almalıdır. Benzer şekilde sayı hissi ile ilişkili kazanım sayısı sadece sayılar ve işlemler öğrenme alanında olması yerine tüm öğrenme alanlarında dengeli bir biçimde yer alması önerilmektedir. Ayrıca programda sayı hissine kavram olarak yer verilmesinin de öğretmenlerin bu kavramı etkili bir şekilde anlayıp kullanmaları için yararlı olacağ1 düşünülmektedir.

\section{Etik Metin}

Bu makalede araştırma ve yayın etiği kuralları takip edilmektedir. Makale ile ilgili her türlü ihlalin sorumluluğu yazar/yazarlara aittir.

\section{KAYNAKÇA}

Acar, S. ve Peker, B. (2019, July). The investigation of the relationship between number sense and algebraic thinking skill. Paper presented at International Conference on Mathematics and Mathematics Education (ICMME 2019). 
Anghılerı, J. (2006). Teaching number sense (2nd ed.). London: Continuum International Publishing Group.

Berch, D.B. (2005). Making sense of number sense: Implications for children with mathematical disabilities. Journal of learning disabilities, 38(4), 333-339.

Burns, M. (2007). About teaching mathematics: A K-8 resource (3th ed.). Math Solution Publications.

Çetin, H. ve Öztürk, Ş. (2020). İlkokul matematik öğretim programının sayı duyusu temel bileşenlerine göre incelenmesi. Ulusal Ĕ̈itim Akademisi Dergisi (UEAD), 4(2), 163-180.

Facun, R.D. ve Nool, N. R. (2012). Assessing the number sense of grade 6 pupils. International Proceedings of Economics Development \& Research, 30, 297-301.

Greeno, J.G. (1991). Number sense as situated knowing in a conceptual domain. Journal for research in mathematics education, 170-218.

Grıffın, S. (2004). Teaching Number Sense. Educational leadership, 61(5), 39.

Gülbağcı Dede, H. (2015). Illköğretim ve ortaöğretim matematik öğretmen adaylarının sayı hissinin incelenmesi (Doktora Tezi). Ulusal Tez Merkezi- İstanbul \& Türkiye

Gülbağcı Dede, H. ve Şengül, S. (2016). İlköğretim ve ortaöğretim matematik öğretmen adaylarının sayı hissinin incelenmesi. Turkish Journal of Computer and Mathematics Education, 7(2), 285-303.

Günkaya, B. (2018). 8.sınıf ögrencilerinin sayı hissi ile uzamsal yetenekleri arasındaki ilişkinin incelenmesi (Yüksek Lisans Tezi). Ulusal Tez Merkezi- İzmir \& Türkiye

Harç, S., (2010). 6. sınıf öğrencilerinin sayı duygusu kavramı açısından mevcut durumlarının analizi (Yüksek Lisans Tezi). Ulusal Tez Merkezi- İstanbul \& Türkiye

Hope, J. (1989). Promoting number sense in school. The Arithmetic Teacher, 36(6), 12.

Howden, H. (1989). Teaching number sense. The Arithmetic Teacher, 36(6), 6-11.

İymen, E. (2012). 8. sını öğrencilerinin üslü ifadeler ile ilgili sayı duyularının sayı duyusu bileşenleri bakımından incelenmesi (Yüksek Lisans Tezi). Ulusal Tez Merkezi- Denizli \& Türkiye

Kaminski, E. (1997). Teacher education students' number sense: Initial explorations. Mathematics Education Research Journal, 9(2), 225-235.

Kaminski, E. (2002). Promoting mathematical understanding: Number sense in action. Mathematics Education Research Journal, 14(2), 133-149.

Karabey, B., Tunalı, C., Olkun, S. \& Ergut, G. (2019). 2009-2013-2017 ortaokul matematik öğretim programlarının sayı duyusu bileşenlerine göre karşılaştırılması. Abant İzzet Baysal Üniversitesi Ĕgitim Fakültesi Dergisi, 19(4), 1760-1774.

Kartal, A. (2016). 8. sınıf ögrencilerinin kesirlerde sayı duyularının incelenmesi (Yüksek Lisans Tezi). Ulusal Tez Merkezi-Rize \& Türkiye

Kayhan Altay, M. (2010). İlköğretim ikinci kademe ögrencilerinin sayı duyularının; sınıf düzeyine, cinsiyete ve sayı duyusu bileşenlerine göre incelenmesi (Doktora Tezi). Ulusal Tez Merkezi- Ankara \& Türkiye 
Kayhan Altay, M. ve Umay, A. (2011). Sınıf öğretmeni adayların hesaplama becerileri ve sayı duyuları arasındaki ilişkinin incelenmesi. e-Journal of New World Sciences Academy, 6(1), 1277-1283.

Kilpatrick, J., Swafford, J. \& Findell, B. (2001). Adding it up: Helping children learn mathematics. Washington, DC: National Academy Press.

Lincoln, Y.S. ve Guba, E.G. (1985). Naturalistic inquiry. Beverly Hills, CA: Sage Publications, Inc.

Markovits, Z. ve Sowder, J. (1994). Developing number sense: An intervention study in grade 7. Journal for Research in Mathematics Education, 4-29.

Mcintosh, A., Reys, B. J. \& Reys, R. E. (1992). A proposed framework for examining basic number sense. For the Learning of Mathematics, 12(3), 2-8.

Merriam, S.B. (1998). Qualitative research and case study applications in education. Jossey-Bass.

Merriam, S.B. (2009). Qualitative research: A guide to design and implementation. Jossey-Bass.

Micklo, S.J. (1999). Estimation it's more than a guess. Childhood Education, 75(3), 142- 145.

Miles, M.B. ve Huberman, A.M. (1994). Qualitative data analysis (2nd ed.). Sage.

Mohamed, M. ve Johnny, J. (2010). Investigating number sense among students. Procedia-Social and Behavioral Sciences, 8, 317-324.

National Council of Teachers of Mathematics (1989). Curriculum and evaluation standards for school mathematics. NCTM

Natínal Council of Teachers of Mathematics (NCTM), (2000). Principles and standards for school mathematics. Reston, VA: National Council of Teachers of Mathematics.

Reys, R., Reys, B., Emanuelsson, G., Johansson, B., Mcintosh, A. \& Yang, D.C (1999). Assessing number sense of students in Australia, Sweden, Taiwan, and the United States. School Science and Mathematics, 99(2), 61-70.

Rosenstein, J.G., Caldwell, J.H. \& Crown, W.D. (1996). New Jersey mathematics curriculum framework.: New Jersey Mathematics Coalition.

Singh, P. (2009). An Assessment of Number Sense among Secondary School Students. International Journal for Mathematics Teaching and Learning, 155, 1-29.

Sowder, J.T. ve Schappelle, B.P. (Eds.). (1989). Establishing foundations for research on number sense and related topics: Report of a conference. San Diego State University, Center for Research in Mathematics and Science Education.

Şengül, S. ve Gülbağcı Dede, H. (2013). Sayı hissi bileşenlerine ait sınıflandırmaların incelenmesi. The Journal of Academic Social Science Studies, 6(8), 645-664.

Şengül, S. ve Gülbağcı Dede, H. (2014). Matematik öğretmenlerinin sayı hissi problemlerini çözerken kullandıkları stratejiler. Turkish Journal of Computer and Mathematics Education (TURCOMAT), 5(1), 73-88.

Şengül, S. ve Gülbağcı, H. (2013). 7. ve 8. Sınıf öğrencilerinin sayı hissi ile matematik öz yeterlikleri arasındaki ilişkinin incelenmesi. International Journal of Social Science, 6(4), 1049-1060. 
Takır, A. (2016). 6., 7. ve 8. Sınıf Öğrencilerinin Sayı Duyusu Becerilerinin Bazı Değişkenler Açısından İncelenmesi. Dicle Üniversitesi Ziya Gökalp Ĕ̆itim Fakültesi Dergisi, 29, 309-323.

Tsao, Y.L. (2004). Effects of a problem-solving-based mathematics course on number sense of preservice teachers. Journal of College Teaching and Learning, 1(2), 33-49.

Tsao, Y.L. ve Lin, Y.C. (2011). The study of number sense and teaching practice. Journal of Case Studies in Education, 2, 1-14.

Verschaffel, L., Greer, B. \& De Corte, E. (2007). Whole number concepts and operations. Second Handbook of Research on Mathematics Teaching and Learning, 2, 557-628.

Yang, D.C. (1995). Number sense performance and strategies possessed by sixth and eighth grade students in Taiwan [University of Missouri, Columbia].

Yang, D.C. (2002). Teaching and Learning Number Sense: One Successful Process-Oriented Activity With Sixth Grade Students in Taiwan. School Science and Mathematics, 102(3), 1-6.

Yang, D.C. (2003). Developing number sense through realistic settings. Australian Primary Mathematics Classroom, 8(3), 12-17.

Yang, D.C. (2005). Number sense strategies used by 6th-grade students in Taiwan. Educational Studies, 31(3), 317-333.

Yang, D.C. (2007). Investigating the strategies used by pre-service teachers in Taiwan when responding to number sense questions. School Science and Mathematics, 107(7), 293-301.

Yang, D.C. ve Wu, W.R. (2010). The study of number sense: Realistic activities integrated into third-grade math classes in Taiwan. The Journal of Educational Research, 103(6), 379-392.

Yang, D.C., Li, M.N. \& Lin, C.I. (2008). A Study of the Performance of 5th Graders in Number Sense and Its Relationship to Achievement in Mathematics. International Journal of Science and Mathematics Education, 6(4), 789-807.

Yapıcı, A. (2013). 5, 6 ve 7. sını öğrencilerinin yüzdeler konusunda sayı duyularının incelenmesi (Yüksek Lisans Tezi). Ulusal Tez Merkezi- Ankara \& Türkiye

Yıldırım A. ve Şimşek, H. (2011). Sosyal bilimlerde nitel araştırma yöntemleri. Ankara: Seçkin Yayıncılık. 


\title{
EXTENDED ABSTRACT
}

\author{
An Analysis of 2018 Secondary School Mathematics Curriculum According to Number \\ Sense Components
}

\section{Introduction}

Number sense is one of the topics that has been studied in recent years and its importance is often emphasized. Teachers have the most important task in giving students the number sense. One of the resources guiding the teachers is the curriculum. For this reason, it is thought that due importance should be given to number sense in the curriculum. In our country, though not directly, the reflections of number sense are observed in the mathematics curriculum. In the main aims of mathematics education, doing mental math and prediction skills are mentioned. However, it is believed that it will also be important to include the gains which are related to number sense and which can improve number sense. In this context, the aim of the study is to examine the 2018 secondary school mathematics curriculum according to the sense of number and its components. In this sense, the most general research problem of the study was determined as "To what extent are the number sense and its components included in the 2018 secondary school mathematics curriculum?".

\section{Method}

Since the study did not aim to study a specific situation, system, culture, or establish a theory, it was conducted with a basic qualitative research design (Merriam, 1998, 2009). In the data collection of the study, a data collection method, document analysis was used. In this context, the data source of the study is the Secondary School Mathematics Curriculum published by the Ministry of National Education in 2018. The data collected in the study were analyzed with descriptive analysis.

\section{Result ve Discussion}

At the first stage of the study, the total number of gains according to grade levels and learning areas were examined. After that, the total number of gains related to the number sense were examined to determine to what extend the number sense was included in the 2018 secondary school mathematics curriculum according to grade level. In this context, it was determined that 28 of 56 gains in 5th grades, 17 of 59 gains in 6th grades, 10 of 48 gains in 7th grades, and 7 of 52 gains in 8th grades were related to number sense. In total, it was seen that 62 of the 215 gains in the curriculum were related to the number sense. In a similar study conducted by Gülbağc1 Dede (2015), the mathematics curriculum in 2009 was examined. As a result of the study, 40 gains in 5th grades, 22 gains in 6th grades, 13 gains in 7th grades and 14 gains in 8th grades were found to be related to number sense. So, the results were similar in both studies. According to the grade levels, the 5th grade is the grade level with the highest number of gains related to the number sense. As a result of the examination of the gains related to number sense in the 2018 secondary school mathematics curriculum according to the number sense components, it was seen that the most gains were in the meaning of numbers component at all grade levels. Karabey, Tunal1, Olkun and Ergut (2019) stated that understanding the meanings of numbers component was among the most used number sense components in the study they examined the 2009-2013-2017 mathematics curriculum. As a result, different study results were consistent with our study. 
In the examination of to what extent the number sense was included in the 2018 middle school mathematics curriculum by learning areas, it was determined that 56 of 106 gains in numbers and operations, 1 of 23 gains in algebra, 5 of 67 gains in geometry and measurement were related to number sense. As a result, it was seen that most of the gains related to number sense in the curriculum were in numbers and operations, and the gains in data processing and probability were not related to number sense. Çetin and Öztürk (2020) decided that in the 2018 elementary school mathematics curriculum, there was the highest number of gains related to the number sense in numbers and operations. Therefore, the results of the two studies were consistent. As a result of the examination of the gains related to number sense in the 2018 secondary school mathematics curriculum according to the number sense components, it was determined that the most gains in all learning areas were in the meaning of numbers component. It was determined that while there were gains for all components in numbers and operations, there were only gains in the meaning of numbers component in algebra. In geometry and measurement, it was observed that there was a gain in the meaning of numbers and the prediction component.

Kaminski (2002) stated that students' understanding and effective use of mathematics is possible with the development of number sense. Therefore, it is recommended to include more number sense in the gains of mathematics in order to better understand mathematics and increase mathematics success. Also, it is thought that including number sense as a concept in the curriculum would be useful for teachers to understand and use this concept effectively.

\section{(ब) $\odot \odot$}

"International Journal of New Approaches in Social Studies - IJONASS" is licensed under a Creative Commons Attribution-NonCommercial-ShareAlike 4.0 International License. 